\title{
Fitting the Causal Model of Marital Relationship Distress Based on the Stigma of Infertility: The Mediating Role of Relational Aggression in Infertile Women
}

Niloofar Mikaeili ( $\square$ nmikaeili@uma.ac.ir)

University of Mohaghegh Ardabili

Habibeh Salvat

Ardabil University of Medical Science

Matine Ebadi

University of Mohaghegh Ardabili

\section{Research Article}

Keywords: Marital Relationship Distress, Infertility Stigma, relational Aggression, Infertile Women

Posted Date: February 3rd, 2022

DOI: https://doi.org/10.21203/rs.3.rs-1241720/v1

License: (c) (i) This work is licensed under a Creative Commons Attribution 4.0 International License.

Read Full License 


\section{Abstract}

The aim of this study was to fit the causal model of marital relationship distress based on infertility stigma mediated by relational aggression in infertile women. The research method was descriptive and structural equations. The statistical population of the study consisted of all infertile women who referred to infertility centers and obstetrics and gynecology medical centers in Tehran in the summer of 1400 and due to lack of full access to them 300 people were selected by simple random sampling method and participated in the research through online questionnaire. Data were collected using the Marital SelfReporting Questionnaire Thakson-Wisman et al. (2009), the Fu et al. (2014) Infertility Stigma, and the Nelson- Carroll (2006) Hidden relational Aggression Questionnaire. Data analysis was performed using structural equation modeling. The results showed that the causal model of the relationship between infertility stigma, relational aggression and marital relationship distress in infertile women was confirmed based on various fit indices. Infertility stigma and associated aggression have a direct effect on the marital turmoil of infertile women; Also, the stigma of infertility through relational aggression has an indirect effect on the marital turmoil of infertile women $(P<0.05)$. It can be effective in reducing the chaos of the marital relationship.

\section{Introduction}

Infertility is one of the most common problems in the world and one of the individual and social problems that can expose people involved to various psychological pressures (1); As defined by the American Reproductive Medical Association as the failure to achieve a successful pregnancy after 12 months or more of the appropriate time for unprotected intercourse; And in a recent analysis of 277 populationbased studies and health surveys around the world, 48.5 million couples have infertility problems, with $13.1-1.9 \%$ prone to primary and secondary infertility, and approximately $8.8 \%$ of all married women aged 15-49 in the United States are infertile (2). Incidence/Occurrence of impulsive behaviors and scattered anger, feelings of worthlessness and inadequacy, worries about sexual attractiveness, feelings of rejection, as well as problems in marital relationships and sexual desires and obliging it due to infertility, reduced quality of life and reduced social relationships These include mental health problems reported by researchers (1). In the meantime; One of the major crises in infertile women is marital stress and turmoil which According to the Fifth Edition of the Statistical and Diagnostic Guide of Mental Disorders, marital turmoil is referred to as "behavioral dysfunction" such as difficulty in resolving (cognitive) conflict such as chronic negative attribution To spouse (and emotional) such as indifference or anger towards partner (defined) (3). Disturbed couples experience marital conflict, emotional conflict, behavior, and threats, and are deeply frustrated and unhappy, and this kind of feeling leads to the dissolution of the marital relationship (4). In contrast, a good relationship free of marital conflict between couples can prevent poor health consequences and increase the quality of life (5).

The most distressing result of infertility is stigma, which is caused by attitudes and prejudices of society. Stigma is having a negative perception of oneself as an infertile woman who has been alienated, isolated and insulted in society (6). Infertility stress in infertile couples, especially infertile women, may be high 
and they may suffer more physically and mentally. Health problems are more prevalent due to both not achieving this important goal of life and the social stigma associated with it, especially in developing countries or third world countries (7). Infertility stigma causes an infertile person to experience discrimination from their spouse or other family members (8). There are three main mechanisms by which infertility stigma is produced and reinforced: Labeling a person who is infertile and The persistence of negative stereotypes related to suspected causes of infertility (e.g., abortion, multiple sexual partners) and the consequences of infertility that reinforce stigma (e.g., social ridicule and distance, divorce) (9). Öztürk et al (2) have shown that infertile women have higher levels of stress and experience stigma and are more exposed to emotional and physical violence; They also have lower support. Li et al. (10) research showed that infertility stress has affected the quality of life of infertile women through marital satisfaction and tolerance. Research of Ergin et al (11) showed that infertility has a significant effect on family attitudes and sexual perception of infertile couples. Behbahani and Mandanizadeh (12) showed that positive and negative fantasies, infertility stigma and psychological distress affected the quality of infertile women 's marital relationships.

One of the most common complaints among couples is the presence of uncontrolled anger that leads to new protest or intensification of existing protests through relational distress (13). Although most research on relational aggression focus on childhood interactions, recent research has been conducted with the aim of understanding relational aggression in the context of romantic relationships, which can be thought of as an inappropriate approach to manage stress, Includes behaviors such as: confrontation, threatening to break up the relationship, ignoring or actively withdrawing. and differs from other definitions of verbal or emotional abuse; Because its focus is on deprivation and the intention to harm interpersonal relationships (14). In this regard, infertility regardless of socio-economic level and Education is associated with partner violence (15). As an example, past studies show $1.8 \%$ of infertile women in Hong Kong, $41.6 \%$ of women in Nigeria, $64 \%$ in Pakistan, $61.8 \%$ Percentage in Iran, $33.6 \%$ in Turkey and $77.8 \%$ in India experienced violence by their partner (16). Research by Sandberg et al. (14) showed that individuals with perceived relational aggression lead to lower Sexual satisfaction for both himself/herself and the partner. Namdarpour and Balkhanabadi (17) showed that Aggression, relational patterns and sexual satisfaction predict marital compatibility. Therefore, given that infertile women are exposed to the negative gaze of others, real or imagined, recognizing the factors that help infertile women to stay calm in these critical times and to solve interpersonal problems and it is very important for them to adopt the turmoil of their marital relationship. It is possible to identify important and effective variables in this field is; therefore, the present study aimed to investigate marital relationship distress based on infertility stigma mediated by aggression Communication was performed in infertile women. Identifying important and effective variables in this field can pave the way for infertile women, infertility specialists and family counselors and psychologists in the community to take interventions to maintain and increase couples' relationships. Inefficiency and misconceptions about infertility, including perceived stigma, have played a significant role in infertile women 's marital disputes; Therefore, the present study was conducted to investigate the marital relationship distress based on infertility stigma mediated by relational aggression in infertile women. 


\section{Method}

Based on the nature and method, the present study is a descriptive-survey research of correlation type and applied in terms of purpose. The statistical population of the study will be all women with primary and secondary infertility diagnoses who referred to infertility centers and obstetrics and gynecology medical centers in Tehran in 1400. According to researchers, the minimum sample size for structural equation modeling studies is 200 people; in the present study, due to the lack of full access to infertile women in Tehran, 300 of them will be selected by available sampling method and will participate in the research through an online questionnaire. Data were collected using the marital Taxon self-report measure (Taxon Wiseman et al. (18), the infertility stigma of Fu et al. (19) and the Nelson and Carroll (20) Hidden relational Aggression Questionnaire.

\section{Marital Taxon Self-Report measure (MTSRM)}

This measure was developed by Wiseman et al. (18) and consists of 10 items adapted from the Marital Distress Questionnaire (MSI_R) to which respondents answered yes or no. This tool measures marital discord and turmoil. This test has time stability and standard validity in distinguishing disturbed couples from non-disturbed couples. The scores of this test range from 0 to 10, that a score of 4 as the cut-off score for marital turmoil. The validity of this questionnaire has been confirmed by its creators and has a reliability above 0.70 (18). In Iran, for the first time, its revised version was implemented by Behradfar et al. (21) in married men and women, and its validity was reported to be 0.94 . In the present study, the reliability of Cronbach's alpha method was 0.79 .

\section{Infertile Stigma Scale (ISS):}

This scale is used as an indicator of perceived stigma and stigma itself for women dealing with the diagnosis and treatment of infertility. This scale was compiled by Fu et al. (19) and consists of 27 items with options in a 5 Likert scale are arranged from strongly disagree $=1$, somewhat disagree $=2$, not sure $=3$, somewhat agree $=4$, and strongly agree $=5$. The minimum and maximum scores in this tool are 27 and 135, respectively. Translation back was used to obtain the Persian version. In the exploratory factor analysis, 4 factors were extracted by rotating the varimax of the Persian version of the infertility stigma scale: personal worthlessness, social withdrawal, general stigma and family stigma. Also, Cronbach's alpha reliability coefficients of the whole scale and 4 extracted factors were satisfactory. There is a significant correlation between retest coefficient (two weeks apart) of 0.58 and this scale with Rosenberg self-esteem scales and general self-efficacy beliefs as divergent validity coefficient and self-critical scale as convergent validity coefficient (22). In the present study, the reliability of Cronbach's alpha method was 0.95 .

\section{The covert relational Aggression Scale (CRAS)}


Designed by Nelson and Carroll in 2006 to measure Adult romantic relationships scale is Linder, Crick, and Collins (23). Covert relational Aggression Scale has 12 items (6 items per subscale). This scale is scored by Likert method according to the answers of 1 to 7 degrees. Carroll et al. (24) reported Cronbach's alpha coefficient of emotional withdrawal scores of 0.90 for husbands and 0.86 for spouses, as well as Cronbach's alpha of deteriorating social prestige 0.88 for husbands and 0.90 for wives. In the study of Meng et al. (25), the results of confirmatory factor analysis show the validity of the original version of the scale. Cronbach's alpha coefficient for social deterioration and emotional withdrawal has also been reported 0/9 and 0/86 in men and 0/88 and 0/9 in women, respectively.. In the present study, the reliability of Cronbach's alpha method was 0.94 .

Methods of implementation and analysis: After obtaining the necessary permits and receiving ethic's code from Mohaghegh Ardabili University, he referred to infertility centers and obstetrics and gynecology medical centers in Tehran and with the coordination of the questionnaires were distributed among infertile women. In This research available sampling method was used. Since the online questionnaire link was broadcast, the link remained active for three weeks, during this time, 300 questionnaires were provided to researchers by eliminating incomplete items. Necessary explanations such as the purpose of the research and how to answer the questions were provided in the questionnaire and individuals participated in this research completely voluntarily.

Inclusion criteria include willingness to participate in the study, failure to achieve a successful pregnancy after 12 months or more of the appropriate time with unprotected intercourse, age range 25 to 45 years, minimum literacy level, no underlying diseases and exclusion criteria this research also includes the unwillingness to cooperate and the distortion of the questionnaire. In this research Common codes of ethics in medical research include 13, 14 and 2 (benefits from the findings for the advancement of human knowledge), code 20 (coordination of research with religious and cultural standards) and codes 1, 3 and 24 (satisfaction of subjects and representatives) have been observed.

\section{Results}

The statistical sample included 300 women with a diagnosis of primary and secondary infertility in Tehran with a mean age of 5.3736 .93 who were in the age range of 25 to 45 years. Most of the participants with $46 \%$ (138 people) have lived together for 5 to 10 years, $52.7 \%$ ( 158 people) have had an infertility period of less than 5 years, 33.3\% (100 people) have a bachelor's degree and $51.7 \%$ (155 people) N) had a moderate economic status.

Table 1 shows the descriptive statistics related to mean, standard deviation, skewness and elongation of the variables of marital relationship distress, infertility stigma and relational aggression. The amount of skewness observed for the research variables is in the range $(-2,2)$; That is, in terms of skewness, the studied variables and their components are normal and their distribution is symmetric. Also, the amount of elongation for the variables of marital relationship distress, infertility stigma and relational aggression 
is in the range $(-2,2)$; this indicates that the distribution of research variables and their components has a normal elongation.

The results of Table 2 show that marital relationship distress was associated with infertility stigma ( $p$ $<0.01, r=0.550)$ and relational aggression $(p<0.01, r=0.531)$ at a significant level of $99 \%$.

In the continuation of the research, using structural equations, the direct and indirect effects of infertility stigma mediated by relational aggression on marital relationship distress in infertile women are investigated. (According to figure 1 and 2 )

According to the obtained results of table 3 , it can be said that the research model is approved in terms of significance and fit indicators.

According to Table 4, the direct effect of infertility stigma variable on marital relationship distress and positive relational aggression is significant; The direct effect of relational aggression variable on marital distress is positive and significant.

To investigate the indirect effect of infertility stigma on marital relationship distress mediated by relational aggression, the Sobel test was used. Also, to determine the intensity of the indirect effect through a mediator, a statistic called VAF is used, which has a value between 0 and 1 ; In fact, this value measures the indirect effect on the total effect.

According to table 5, the amount of indirect t-statistic (t-sub) between the above variables which is out of range (1.96 \& -1.96); Therefore, the hypothesis of the indirect effect of infertility stigma on marital distress is accepted. Therefore, in addition to the direct effect, the infertility stigma variable also indirectly affects the distress of the marital relationship through relational aggression. According to the obtained rate for VAF statistics, it can be seen that $45.5 \%$ of the effect of infertility stigma on marital distress can be explained through relational aggression.

\section{Discussion}

The aim of this study was to investigate the causal model of marital relationship distress based on infertility stigma mediated by relational aggression in infertile women. The results showed that the effect of infertility stigma on marital distress of infertile women was positive and significant. Results obtained with the research findings of (2); (10); (11) and (12) were consistent. The study of Ergin et al. (11) showed that infertility has a significant effect on family attitudes and sexual perception of infertile couples. Communities normally expect couples to reproduce. For people who grow up with these cultural norms, infertility makes them unable to meet social expectations, especially infertile women tending to report more negative emotions, stress, emotional reactions, and They have consequences of failure (2). In other words; Infertility is not only a gynecological disease, but also a bio-psychosocial health problem including poor quality of life, psychiatric problems, marital conflicts and sexual dissatisfaction (25). Having a child is an effective factor in gaining social status in women. In Iran, as in many societies around the world, the 
lack of pregnancy and infertility is often severely stigmatized, leading to deep social suffering for infertile couples, so that infertile women perceive a higher level of loneliness. In addition, marital relationships may be damaged by a diagnosis of infertility, as couples are often confused about ways to deal with the disease.

The results showed that relational aggression has a direct and significant effect on the marital relationship distress of infertile women. These results are consistent with the results of research by (14); (15) and (17). Sandberg et al. (14) showed that individuals with perceived relational aggression lead to lower sexual satisfaction for both themselves and their partner. Infertility is a stressful process for women and causes anxiety, depression, and consequently low adjustment that may lead to maladaptive behaviors by the husband (27); In other words, it is not far-fetched that covert relational aggression, which includes slandering a spouse, gossiping about him or her, telling the spouse private information to others, or allowing others to interfere in arguments and disputes between spouses, ignoring the spouse and not paying attention to him or her. Failure to have sex and threatening to break up has a negative effect on agreement, satisfaction and marital cohesion. be; In other words, infertile women may show aggressive behaviors due to the unpleasant feelings they experience, which in turn leads to increased aggression. The results also showed that the indirect effect of infertility stigma on marital relationship distress in infertile women through relational aggression was significant. Therefore, relational aggression was accepted as a mediator of the relationship between infertility stigma and marital relationship distress in infertile women and it was observed that $45 \%$ of the effect of infertility stigma on marital relationship distress in infertile women can be explained through relational aggression. No study was found to be directly consistent with these results. Azturk et al. (2) showed that infertile women experienced high levels of stigma and stress, with 1 in 5 experiencing emotional or physical violence. A growing body of research conducted mainly on low- and middle-income individuals shows that infertility is associated with sexual partner violence, regardless of socioeconomic and educational levels (Stellar et al., 2016). In other words, the unpleasant experiences that infertile women experience and lead to the perception of stigma by their husbands and those around them, gradually have a negative effect on their marital relationships, which leads to relational aggression. Will go.

\section{Limitations}

In this study, the characteristics of the spouse such as occupation, level of education and the existence of a male cause of infertility that can lead to mental distresss in infertile women were not examined, which should be considered in future research. Another point is that the present study needs to be interpreted and taking into account by the existing limitations. The first limitation is the use of self-report scales to evaluate research variables. It is suggested that qualitative research methods be used for future research and that research be conducted on men and couples as well.

\section{Conclusions}


Since women's health is the basis of family and community health and its provision is not possible without improving the relationship between husbands, so the results of this study can help therapists and family counselors to increase awareness, the degree of relational aggression reduce them and thus reduce their marital turmoil. Also, the results, in addition to enriching the research literature, can pave the way for various researchers to study marital problems perceived by infertile women.

\section{Declarations}

\section{Ethics approval and consent to participate}

The protocol was conducted in accordance with the latest version of the Declaration of Helsinki and was approved by the Institutional Review Board and ethical committee at the Ardabil University of Medical Sciences. We obtained the written informed consent form the participated before participation in the study. The ethical approval was obtained from the ethics committee review board in the Ardabil University of Medical Sciences with ethics ID IR.UMS.REC.1400.021 and can be viewed on the website of the National Ethics Committee website.

\section{Consent for publication}

Not applicable.

\section{Availability of data and materials}

The datasets generated and/or analyzed during the current study are not publicly available in order to maintain the anonymity of the participants. The data can be made available from the corresponding author on reasonable request.

\section{Declaration of Competing Interest}

All other declare no competing interests.

\section{Funding}

This research didn't receive any grant from any funding agency in the public, commercial or not-for-profit sectors.

\section{Authors' contributions}


NM conceived the study. ME \& NM collected the data and interpreted the data. HS wrote the first draft. NM \& ME revised and reviewed. All authors read and approved the final manuscript.

\section{Acknowledgement}

The researchers announced their gratitude to all parents and children who participated in this study, as well as to the honorable authorities of Ardabil Medical University, who are fully committed to this study.

\section{References}

1. Hocaoglu, C. (2019). The psychosocial Aspect of Infertility. Infertility, Assisted Reproductive Technologies and Hormone Assays. doi: 18222 /intechopen.112.

2. Öztürk, R., Bloom, T. L., Li, Y., \& Bullock, L. F. (2021). Stress, stigma, violence experiences and social support of us infertile women. Journal of reproductive and infant psychology, 39(2), 205-217.

3. American Psychiatric Association. (2013). Diagnostic and Statistical Manual of Mental Distresss, Fifth Edition. Arlington, VA, American Psychiatric Association.

4. Beach, S. R., Wamboldt, M. Z., Kaslow, N. J., Heyman, R. E., First, M. B., Underwood, L. G., \& Reiss, D. (Eds.). (2007). Relational processes and DSM-V: Neuroscience, assessment, prevention, and treatment. American Psychiatric Pub.

5. Tu, K. M., Erath, S. A., \& El-Sheikh, M. (2016). Coping responses moderate prospective associations between marital conflict and youth adjustment. Journal of Family Psychology, 30(5), 523.

6. Yilmaz, E., \& Kavak, F. (2019). The effect of stigma on depression levels of Turkish women with infertility. Perspectives in psychiatric care, 55(3), 378-382.

7. Xu, H., Ouyang, N., Li, R., Tuo, P., Mai, M., \& Wang, W. (2017). The effects of anxiety and depression on in vitro fertilisation outcomes of infertile Chinese women. Psychology Health \& Medicine, 22(1), 3743. https://doi.org/10.1080/13548506.2016.1218031

8. Goffman, E. (2010). Stigma: notes on the managementof spoiled identity. New York: Prentice-Hall.

9. Bornstein, M., Gipson, J. D., Failing, G., Banda, V., \& Norris, A. (2020). Individual and community-level impact of infertility-related stigma in Malawi. Social Science \& Medicine, 251, 112910.

10. Li, X., Ye, L., Tian, L. et al. Infertility-Related Stress and Life Satisfaction among Chinese Infertile Women: A Moderated Mediation Model of Marital Satisfaction and Resilience. Sex Roles, 82, 44-52 (2020). https://doi.org/10.1007/s11199-019-01032-0.

11. Ergin, R. N., Polat, A., Kars, B., Öztekin, D., Sofuoğlu, K., \& Çalışkan, E. (2018). Social stigma and familial attitudes related to infertility. Turkish journal of obstetrics and gynecology, 15(1), 46.

12. Behbahani Mandizadeh, A., Homaei, R. (2020). The casual relationship Stigma infertility and psychological distress with quality of marital relationship through the mediation of meta-emotion in infertile women. Journal of Family Research, 16(1), 55-76. 
13. Askari, I. (2019). The role of the belief system for anger management of couples with anger and aggression: A cognitive-behavioral perspective. Journal of Rational-Emotive \& Cognitive-Behavior Therapy, 37(3), 223-240.

14. Sandberg, J., Meservy, M. V., Bradford, A., \& Anderson, S. (2018). Examining the influence of relational aggression on sexual satisfaction with attachment behaviors as a potential mediator. Journal of sex \& marital therapy, 44(5), 425-437.

15. Stellar, C., Garcia-Moreno, C., Temmerman, M., \& Van Der Poel, S. (2016). A systematic review and narrative report of the relationship between infertility, subfertility, and intimate partner violence. International Journal of Gynecology and Obstetrics, 133(1), 3-8.

16. Ardabily, H. E., Moghadam, Z. B., Salsali, M., Ramezanzadeh, F., \& Nedjat, S. (2011). Prevalence and risk factors for domestic violence against infertile women in an Iranian setting. International Journal of Gynecology and Obstetrics, 112(1), 15-17. https://doi.org/10.1016/j.ijgo.2010.07.030

17. Namdarpour, F., Bolghan-Abadi, M. (2019). Study of the role of Aggression, Communication Patterns, Sexual Satisfaction in Predicting the Dyadic Adjustment. Journal of Research in behavioural Sciences. 16 (3),255-263

18. Whisman, M. A., Snyder, D. K., \& Beach, S. R. (2009). Screening for marital and relationship discord. Journal of Family Psychology, 23(2), 247.

19. Fu, B., Qin, N., Cheng, L., Tang, G., Cao, Y., Yan, C., Zhu, S., \& Lei, J. (2015). Development and validation of an Infertility Stigma Scale for Chinese women. Journal Psychosomatic Research, 79(1), $69-75$.

20. Nelson, D. A., \& Carroll, J. S. (2006). Couples relational aggression and victimization scale (CRAViS). Provo, UT: RELATE Institute.

21. Behrad Far, R., Jazayeri, R., Bahrami, F., Abedi, M., Etemadi, O., Fatemi, S. (2017). Assessment and Clinical Diagnosis in Couple Therapy; Revision and Scrutiny for Psychometrics of the Screening Scale for Marital and Relationship Discord (SSMRD). Journal of Family Research, 12(3), 413-435.

22. Rajabi G, Amiri Asl J, Jelodari A. (2017). Assessing Reliability and Validity of the Persian version of Infertility Stigma Scale (ISS) in Infertile Women. Avicenna J Nurs Midwifery Care, 25 (4), 104-113.

23. Linder, J. R., Crick, N. R., \& Collins, W. A. (2002). Relational aggression and victimization in young adults' romantic relationships: Associations with perceptions of parent, peer, and romantic relationship quality. Social Development, 11(1), 69-86.

24. Carroll JS, Nelson DA, Yorgason JB, Harper JM, Ashton RH, Jensen AC. (2010). Relational aggression in marriage.Aggressive Behavior, 36(5), 315-29.

25. Meng, K. N. (2013). Couple implicit rules for facilitating disclosure and relationship quality with romantic relational aggression as a mediator. Brigham Young University.

26. Onat, G., \& Beji, N. K. (2012). Effects of infertility on gender differences in marital relationship and quality of life: a case-control study of Turkish couples. European Journal of Obstetrics \& Gynecology and Reproductive Biology, 165(2), 243-248. 
27. Ghaffari M, Ramazani N. (2019). Marital Justice and Marital Quality: Mediator Effects for Covert Relational Aggression. Journal of Family Research, 15(4), 487-503.

\section{Tables}

Table 1

Descriptive statistics of research variables

\begin{tabular}{|lllll|}
\hline variable & mean & पstandard deviation & Skewness & Kurtosis \\
\hline marital relationship distress & 4.62 & 1.62 & -0.51 & 0.03 \\
\hline infertility stigma & 84.60 & 16.72 & -1.01 & -0.26 \\
\hline personal worthlessness & 31.10 & 6.48 & -0.79 & -0.38 \\
\hline Social withdrawal & 28.47 & 5.35 & -1.03 & 0.19 \\
\hline General stigma & 12.13 & 2.99 & -0.61 & -0.69 \\
\hline Family stigma & 12.89 & 3.03 & -0.78 & -0.55 \\
\hline Relational aggression & 45.94 & 11.44 & -0.73 & -0.91 \\
\hline Emotional withdrawal & 23.19 & 6.26 & -0.77 & -0.96 \\
\hline Deteriorating social prestige & 22.76 & 5.62 & -0.49 & -0.74 \\
\hline
\end{tabular}

Table 2

Correlation matrix of research variables

\begin{tabular}{|llll|}
\hline variables & $\begin{array}{l}\text { marital relationship } \\
\text { distress }\end{array}$ & $\begin{array}{l}\text { Infertility } \\
\text { stigma }\end{array}$ & $\begin{array}{l}\text { Relational } \\
\text { aggression }\end{array}$ \\
\hline $\begin{array}{l}\text { marital relationship } \\
\text { distress }\end{array}$ & 1 & & \\
\hline Infertility stigma & $0.501^{\star *}$ & 1 & 1 \\
\hline Relational aggression & $0.531^{\star *}$ & $0.632^{\star *}$ & 1 \\
\hline
\end{tabular}


Table 3

Research model fit index

\begin{tabular}{cccc}
\hline Index name & the amount of & Acceptable range & Result \\
\hline$\frac{\chi^{2}}{d_{f}}$ & 2.72 & Less than 3 & acceptable \\
RMSE & 0.076 & $\begin{array}{l}\text { Good: less than 0.08 } \\
\text { Average: } 0.08 \text { to } 0.1\end{array}$ & Good \\
CFI & 0.91 & More than 0.90 & acceptable \\
NFI & 0.92 & More than 0.90 & acceptable \\
GFI & 0.86 & More than 0.80 & acceptable \\
\hline
\end{tabular}

Table 4

Structural equations of the research model

\begin{tabular}{cccccc}
\hline & variables & $\begin{array}{c}\text { Path } \\
\text { coefficient }\end{array}$ & $\begin{array}{c}\text { The amount } \\
\text { of T }\end{array}$ & $\begin{array}{c}\text { standard } \\
\text { error }\end{array}$ & Significance \\
\hline $\begin{array}{c}\text { Infertility } \\
\text { stigma }\end{array}$ & $\rightarrow \quad \begin{array}{c}\text { Marital relationship } \\
\text { turmoil }\end{array}$ & 0.31 & 4.66 & 0.087 & Significant \\
$\begin{array}{c}\text { Infertility } \\
\text { stigma } \\
\text { Relational } \\
\text { aggression }\end{array}$ & $\rightarrow \quad \begin{array}{c}\text { Relational } \\
\text { aggression }\end{array}$ & 0.68 & 9.84 & 0.049 & Significant \\
\hline $\begin{array}{c}\text { Marital relationship } \\
\text { turmoil }\end{array}$ & 0.38 & 5.64 & 0.080 & Significant \\
\hline
\end{tabular}

Table 5

Results of the analysis of the indirect effects of infertility stigma on marital relationship distress mediated by relational aggression

\begin{tabular}{llcccc}
\hline & Reseach hypothesis & T-sobel & $\begin{array}{c}\text { Standard path } \\
\text { coefficient }\end{array}$ & $\begin{array}{c}\text { VAF } \\
\text { statistics }\end{array}$ & Test result \\
\hline $\begin{array}{c}\text { Infertility } \\
\text { stigma }\end{array} \rightarrow \begin{array}{l}\text { Relational } \\
\text { aggression } \rightarrow\end{array}$ & $\begin{array}{c}\text { Marital } \\
\text { relationship } \\
\text { turmoil }\end{array}$ & 5.707 & 0.258 & 0.455 & Confirmation \\
\hline
\end{tabular}

